\title{
Adaptive changes in energy expenditure during mild and severe feed restriction in the rat
}

\author{
BY PATRICK C. EVEN AND S. NICOLAÏDIS \\ Laboratoire de Neurobiologie des Régulations, C.N.R.S. URA 637, Collège de France, \\ 11 Place M. Berthelot, F75231 Paris Cédex 05, France
}

(Received 30 July 1992 - Accepted 20 November 1992)

\begin{abstract}
Using a new-generation open-circuit calorimeter capable of monitoring the cost of activity, and thereby both the real thermic effect of feeding (TEF) and basal metabolism in free-moving freely-feeding rats, we have reassessed the proposal that when food intake is restricted an adaptative reduction in energy expenditure participates in the achievement of energy balance. Total energy expenditure, energy expenditure due to spontaneous activity, TEF, basal energy expenditure and respiratory quotient (RQ) were computed by indirect calorimetry in rats given either a mildly restricted (MR) feed intake for 20-30 d (17 $\mathrm{g}$ feed/d) or a severely restricted (SR) feed intake for $1-10 \mathrm{~d}(4 \mathrm{~g}$ feed/d). In MR rats no significant changes in any of the measured variables were observed. In contrast, SR rats exhibited an adaptative reduction in energy expenditure due to a reduced spontaneous activity and probably also due to a reduced basal energy expenditure. On the other hand none of the animals fed on a restricted feed intake showed an adaptative TEF decrease, suggesting that TEF under ad lib. feeding is rather an obligatory process that does not include an adaptative component. Taken together, these results point out that under restricted feeding most of the decrease in energy expenditure is associated with simple passive mechanisms, such as body weight loss, and with the reduced feed intake per se. Only under severe feed restriction can some additional energetic economy be obtained from a possible reduction of basal metabolism, and to some extent from reduced activity.
\end{abstract}

Calorimetry: Energy expenditure: Thermic effect of feeding: Respiratory quotient: Feed restriction

It has often been suggested that the decrease in whole-body total energy expenditure (TEE) observed during feed restriction is not only due to the loss of metabolically active tissues, but also to a decrease in the metabolic rate of the remaining tissues (Benedict $\&$ Fox, 1934; Westerterp, 1977; Apfelbaum, 1978; Forsum et al. 1981; Bessard et al. 1983; Hill et al. 1985). However, this phenomenon remains controversial since it has not been demonstrated in several recent reports (McCarter et al. 1985; Yu et al. 1985; McCarter et al. 1989). Therefore, the question remains as to whether animals adapt to a shortage of energy supply and, if so, how they do so.

In conditions where the thermoregulatory efforts are minimized, TEE results from the sum of the energy expended for basal metabolism, locomotor activity and feeding. In previous studies the precise measurement of spontaneous activity was not possible in experiments involving the laboratory rat and, therefore, the energy expended in relation to activity and its role in adaptation to feed restriction could not be assessed. In addition, since activity can affect the measurement of the thermic effect of feeding (TEF) or of basal metabolism, it is not possible to report accurately increases or decreases in the magnitude of these components when using traditional calorimeters that do not include the measurement of activity.

In this study we performed metabolic measurements on rats by means of a newgeneration metabolic device that, in addition to TEE, allows the quantification of the 
spontaneous locomotor activity and its metabolic cost simultaneously with the measurement of feed intake and its thermogenic consequences (Even \& Nicolaïdis, 1984, 1985; Even et al. 1988). Using this device we measured the changes induced by either mild or severe feed restriction on TEE and on the energy expended in relation to spontaneous activity and feeding. Restriction rather than starvation was preferred in this study because starvation is known to produce some specific disturbances such as starvation diabetes or gastrointestinal hyposecretion (Kershaw et al. 1960). In addition, feed restriction rather than starvation is closer to the numerous situations, particularly in humans, where the question of metabolic efficiency is raised.

\section{MATERIALS AND METHODS}

Animals and housing

Twenty-eight male Wistar rats, housed in individual cages in a temperature-controlled room $\left(26^{\circ}\right)$ and maintained on a $12 \mathrm{~h}$ light-dark cycle, were used. Water was available $\mathrm{ad}$ lib. The feed was a standard laboratory chow (Extralabo M25 in powder form; Ets, Pietrement, Provins, France) containing $(\mathrm{g} / \mathrm{kg})$ : carbohydrates 481, protein 242, fat 50, water 120, vitamins and minerals 74 . Feed was available according to the experimental schedule. Before the experiments, all rats were fed $a d$ lib. and allowed at least $15 \mathrm{~d}$ to adapt to the conditions of the laboratory.

The mild feed restriction schedule was aimed at reproducing a phenomenon observed in a previous study, i.e. rats given a constant but restricted amount of chow throughout the experiment first lose body weight and then slowly reverse their weight profile to be once again in positive balance (Even \& Nicolaïdis, 1981). The group given a mildly restricted (MR) feed intake consisted of six 8-week-old rats initially weighing 300-320 g offered $17 \mathrm{~g}$ feed $/ \mathrm{d}$ ( $70 \%$ of their previously measured spontaneous feed intake). Feed was given in two meals ( $4 \mathrm{~g}$ at 10.00 hours and $13 \mathrm{~g}$ at 18.00 hours) and the rats were maintained for at least $20 \mathrm{~d}$ under this restricted feeding schedule until they weighed $265.5 \mathrm{~g}$ (SE 2.4) and were again in positive energy balance (gaining $1.7 \mathrm{~g} / \mathrm{d}$ on average). At this reduced body weight these rats were placed in the calorimetric device for measurement of the components of their TEE.

The group given a severely restricted (SR) feed intake consisted of five 8-week-old rats initially weighing $300-320 \mathrm{~g}$ offered $4 \cdot 2 \mathrm{~g}$ feed/d during $10 \mathrm{~d}$. Feed restriction started the same day for the five rats. The feed was given in one meal at 18.00 hours. The calorimetric measurements of energy expenditure were performed in each rat on two occasions at $5 \mathrm{~d}$ intervals; day 1 and 6 of feed restriction in rat 1, days 2 and 7 in rat 2, and so on for the five rats throughout the $10 \mathrm{~d}$ of the experiment.

The non-restricted control group consisted of seventeen rats fed ad lib. and with a large range of body weights $(220-420 \mathrm{~g})$ and ages (6-12 weeks). Five of these rats with an average body weight comparable to the MR rats at the time of experiment (250-300 g) were maintained on a feeding schedule in which feed was not available between 10.00 and 18.00 hours. This schedule did not modify daily feed intake and body weight gain (because spontaneous feed intake is usually negligible during this period) and allowed assessment of the post absorptive energy expenditure needed in the computation of the energy expenditure due to feeding (see p. 423).

\section{Methods}

The calorimetric device used in this experiment to measure simultaneously TEE, spontaneous activity and feeding has been described in detail in previous reports (Even \& Nicolaïdis, 1984, 1985; Even et al. 1988). Briefly, this device is based on the principle of 
open-circuit flow-through calorimetry. Outdoor air is aspirated through the chamber housing the rat $(1.5$ litres/min) by a Wab type peristaltic pump. Cage air is then directed to an air dryer (filled with anhydrous $\mathrm{CaCl}_{2}$ ), a flowmeter, and an $\mathrm{O}_{2}$ and a $\mathrm{CO}_{2}$ analyser. Data from the device are collected by a computer and stored on floppy disks for subsequent analysis. The measurement of airflow and changes in $\mathrm{O}_{2}$ and $\mathrm{CO}_{2}$ content of the air that passed through the chamber give measurements of $\mathrm{O}_{2}$ consumption and $\mathrm{CO}_{2}$ release. Total metabolic rate (watts) is computed from $\mathrm{O}_{2}$ consumption and $\mathrm{CO}_{2}$ release using Lusk's (1928) equation. Feed intake is measured by a micro-balance weighing the food-cup. Spontaneous activity is quantified by integrating the electrical signal produced by three piezoelectric differential force transducers located under the cage housing the rat and responding to changes in pressure produced on the floor of the cage by the movements of the rat. In a series of preliminary reports we have shown that the metabolic cost (that is the increase in metabolic rate) of the various types of spontaneous activities (e.g. grooming, scratching, standing up is linearly correlated with the electrical signal produced by the force transducers, and that the coefficient of proportionality is essentially constant regardless of the body weight of the rat or of the type of activity performed (Even \& Nicolaïdis, 1984). In addition, the diffusion of the respiratory exchanges in the metabolic chamber has been fitted to a model, and the predictions of the model are used to feed a process of numerical fitting capable of correcting the variables of the model, among which is the cost of activity, to best adjust the predictions of the model with the experimental results (Even et al. 1991).

In the routine experiment the rats were weighed then housed in the metabolic chamber at 10.00 hours for a $22 \mathrm{~h}$ uninterrupted recording session $(2 \mathrm{~h}$ are needed for cleaning, resetting and calibrating the system). All measurements were made at $10 \mathrm{~s}$ intervals. During these experiments the temperature in the cage was kept constant at $26( \pm 1)^{\circ}$. At the end of the session the rats were weighed again. All body weight levels reported on pp. 424-426 are the average of these two measures.

The energy expended in relation to activity has been computed by integrating the increases in TEE induced by the spontaneous activity (see above).

TEF has been computed as the cumulative increase in TEE induced by feeding and corrected for the energy expended specifically in relation to activity. In order to prevent irrelevant changes of metabolism, the routine feeding pattern was maintained for each group of subjects. Therefore, TEF was measured during the ad lib. intake of the five rats of the control group that had had no access to food between 10.00 and 18.00 hours, from the $17 \mathrm{~g}$ feed ingested in two meals of the MR group, and from the single $4 \mathrm{~g}$ meal of the SR rats. This allowed investigation of TEF under the daily feeding conditions prevailing in the various groups and participating in their actual energy balance.

\section{Statistical procedures}

Results are presented as means with their standard errors. The statistical significance of correlations between variables was assessed using analysis of variance. Statistical comparisons between groups were made by using Wilcoxon-Mann-Witney two-samples test (two-tailed probabilities). Significances were reported when the probability of the mean difference was $P<0 \cdot 05$.

\section{RESULTS}

TEE and spontaneous food intake in the control rats. Under our experimental conditions it was observed that TEE of the ad lib. fed rats could be predicted accurately from their body weight.

$$
\mathrm{TEE}=1.46+0.556 \mathrm{BW}(n 17, r 0.861, P<0.001),
$$

where TEE is in $\mathrm{kJ} / 24 \mathrm{~h}$ and $\mathrm{BW}$ is body weight in $\mathrm{g}$. 
Table 1. Comparison of total energy expenditure (TEE), basal energy expenditure (BEE) and feed intake $(F I)$ between control and mildly restricted $(M R)$ rats of comparable body weight $(B W)^{*}$

(Mean values with their standard errors)

\begin{tabular}{|c|c|c|c|c|c|c|c|c|c|}
\hline \multirow[b]{2}{*}{ Group } & \multirow[b]{2}{*}{$n$} & \multicolumn{2}{|c|}{$\mathrm{BW}(\mathrm{g})$} & \multicolumn{2}{|c|}{$\operatorname{TEE}(\mathrm{kJ} / 22 \mathrm{~h})$} & \multicolumn{2}{|c|}{ FI $(\mathrm{g})$} & \multicolumn{2}{|c|}{$\operatorname{BEE}(\mathrm{kJ} / 22 \mathrm{~h})$} \\
\hline & & Mean & $\mathrm{SE}$ & Mean & $\mathrm{SE}$ & Mean & $\mathrm{SE}$ & Mean & $\mathrm{SE}$ \\
\hline Control & 7 & 267 & 10 & $148 \cdot 9$ & $5 \cdot 6$ & $16 \cdot 8$ & $3 \cdot 7$ & $97 \cdot 4$ & 2.9 \\
\hline $\mathrm{MR}$ & 6 & 265 & 3 & $145 \cdot 4$ & $5 \cdot 6$ & $17 \cdot 0$ & 0.0 & $94 \cdot 2$ & $5 \cdot 2$ \\
\hline
\end{tabular}

* For details of diets and experimental procedures, see pp. 422-423.

Attempts to use the classic allometric functions using body weight ${ }^{(0.75)}$ (Kleiber, 1947) or body weight ${ }^{(0.62)}$ (Heusner, 1982) to predict TEE from body weight did not improve the correlation observed and, in contrast, estimated non-zero TEE levels for zero body weight. Such a result indicates that in our experimental conditions body weight predicted better than body weight ${ }^{(0.75)}$ or body weight ${ }^{(0 \cdot 62)}$ for the TEE of the ad lib.-fed rat.

In the same way, spontaneous feed intake of the seventeen ad lib.-fed rats of this study was found to be closely related to body weight in a linear fashion:

$$
\mathrm{FI}=-5 \cdot 70+0 \cdot 0844 \mathrm{BW}(n 17, r 0 \cdot 882, P<0 \cdot 001) \text {, }
$$

where FI is feed intake in $\mathrm{g}$ and $\mathrm{BW}$ is body weight in $\mathrm{g}$.

$T E E$ and feed intake in the MR rats. According to the correlation between feed intake and body weight in the ad lib.-fed rats it appeared that the $265 \mathrm{~g}$ body weight at which the rats restricted to $17 \mathrm{~g}$ feed $/ \mathrm{d}$ had stabilized their body weight was very close to the $269 \mathrm{~g}$ predicted body weight of younger ad lib.-fed rats eating the same amount of food (from equation $2, \mathrm{BW}=(\mathrm{FI}+5 \cdot 70) / 0 \cdot 0844$; therefore, body weight expected from an ad lib-fed rat eating $17 \mathrm{~g}=(17+5 \cdot 70) / 0 \cdot 0844$, ie. $268 \cdot 9 \mathrm{~g})$.

Similarly, according to the correlation between TEE and body weight, an ad lib.-fed rat weighing $265 \mathrm{~g}$ could be expected to have a TEE of $149 \mathrm{~kJ}$ (from equation 1, $\mathrm{TEE}=1.46+(0.556 \times 265)=148.8)$, i.e. a level very close to $145.4 \mathrm{~kJ}$ observed in the $265 \mathrm{~g}$ feed-restricted rats. In other words, the MR rats reached a plateau of body weight and had a TEE close to those of younger ad lib.-fed rats exhibiting similar weights and intakes. This was statistically confirmed by a direct comparison of TEE and feed intake between the MR rats and a sample of seven of the seventeen control rats that had a body weight very close to the body weight of the feed-restricted rats (Table 1). In addition, comparison with the whole pool of control rats using the slope of the correlation between TEE and body weight to extrapolate all TEE levels at $310 \mathrm{~g}$ (average body weight of the seventeen control rats) confirmed this observation (Table 3, Fig. 1).

$T E E$ and feed intake in the $S R$ group. In contrast to MR rats, during severe feed restriction feed intake as well as TEE was obviously reduced compared with feed intake and TEE in ad lib.-fed rats of similar body weight. The direct comparison of TEE in the SR rats with TEE in samples of the seventeen ad lib.-fed rats of similar body weight clearly showed that severe feed restriction induced a progressive decrease in TEE that reached significance during the second $5 \mathrm{~d}$ of feed restriction (Table 2). The decrease in TEE of the SR rats was confirmed by comparing it with the TEE prevailing in the whole pool of control rats, as it was calculated from the linear regression linking the various weights to their respective TEE. Given the power of this method, due to the large number obtained from the control 


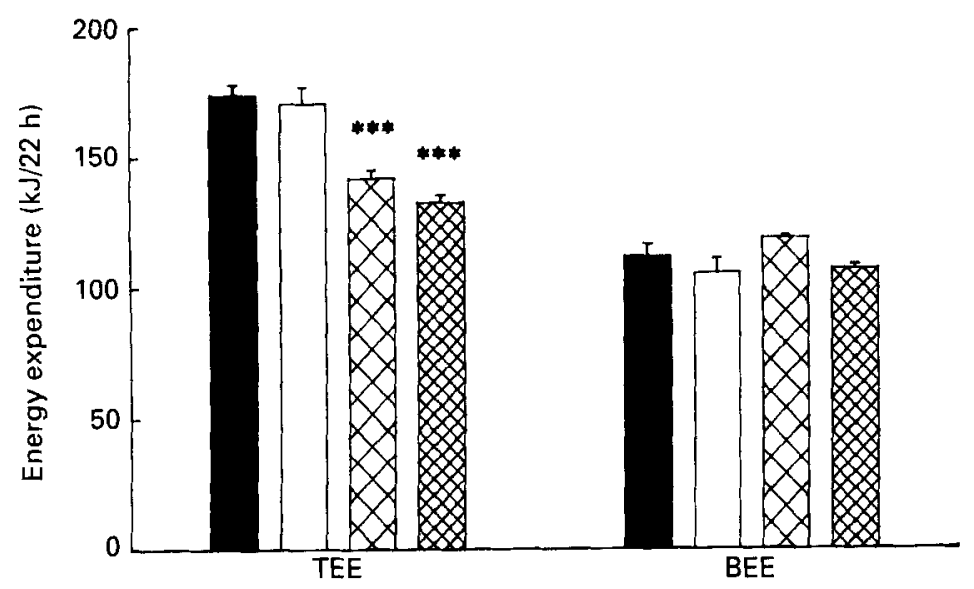

Fig. 1. Total (TEE) and basal energy expenditure (BEE) adjusted for a body weight of $310 \mathrm{~g}$ in the control ( $\boldsymbol{\square}$ ), mildly restricted $(\square)$, severely restricted on days 1 to $5(\mathbb{B})$ and severely restricted on days 6 to 10 (国) rats (from Table 3). Values are means with their standard errors, represented by vertical bars. The reduction of the SEM allowed by the standardization of the data reveals the rapid decrease of TEE in SR rats and, in contrast, the small changes induced by feed restriction in BEE. Mean TEE values of SR rats were significantly different from control values: ${ }^{* * *} P<0.001$.

Table 2. Comparison of total energy expenditure (TEE), basal energy expenditure (BEE) and feed intake $(F I)$ between control and severely restricted $(S R)$ rats of comparable body weight $(B W) \dagger$

(Mean values with their standard errors)

\begin{tabular}{|c|c|c|c|c|c|c|c|c|c|}
\hline & \multirow[b]{2}{*}{$n$} & \multicolumn{2}{|c|}{ BW (g) } & \multicolumn{2}{|c|}{$\operatorname{TEE}(\mathrm{kJ} / 22 \mathrm{~h})$} & \multicolumn{2}{|c|}{ FI $(g)$} & \multicolumn{2}{|c|}{$\operatorname{BEE}(\mathrm{kJ} / 22 \mathrm{~h})$} \\
\hline & & Mean & $\mathrm{SE}$ & Mean & SE & Mean & $\mathrm{SE}$ & Mean & $\mathrm{SE}$ \\
\hline \multicolumn{10}{|l|}{ Days 1-5 } \\
\hline Control & 9 & 307 & 16 & $169 \cdot 7$ & $14 \cdot 6$ & $20 \cdot 6$ & $2 \cdot 8$ & $104 \cdot 7$ & $16 \cdot 4$ \\
\hline SR & 5 & 308 & 27 & $140 \cdot 9$ & $12 \cdot 0$ & $4 \cdot 2$ & $0 \cdot 0$ & $117 \cdot 7$ & $9 \cdot 9$ \\
\hline \multicolumn{10}{|l|}{ Days 6-10 } \\
\hline Control & 7 & 277 & 7 & 153.5 & $5 \cdot 8$ & $17 \cdot 8$ & 0.9 & $98 \cdot 8$ & $2 \cdot 7$ \\
\hline SR & 5 & 276 & 9 & $113 \cdot 3^{*}$ & $5 \cdot 7$ & $4 \cdot 2$ & $0 \cdot 0$ & 94.9 & $4 \cdot 5$ \\
\hline
\end{tabular}

Mean value for SR rats was significantly different from the control value: ${ }^{*} P<0 \cdot 05$.

$\dagger$ For details of diets and experimental procedures, see pp. 422-423.

group, it was possible to show that the decrease in TEE of the SR rats was significant, even in the first $5 \mathrm{~d}$ period of deprivation (Table 3, Fig. 1).

Energy expenditure due to activity. Comparison of the levels of energy expenditure due to activity revealed that it was very similar in control and MR rats, but decreased progressively in the SR rats. This decrease was particularly clear-cut during the last $5 \mathrm{~d}$ of the severe feed restriction period ( $-50 \%$; Table 4$)$. The reduced body weight of the SR rats accounted for only $6 \%$ of this phenomenon. Indeed, when corrected for $100 \mathrm{~g}$ body weight the energy expended in activity still showed a significant $44 \%$ decrease in the SR rats during the last $5 \mathrm{~d}$ of feed restriction (Table 4).

$T E F$. TEF averaged $15 \%$ of ingested calories in the ad lib.-fed rat, and was not modified 
Table 3. Comparison of the total (TEE) and basal (BEE) energy expenditure between control, mildly restricted $(M R)$ and severely restricted $(S R)$ rats computed for a body weight of $310 \mathrm{~g}$ (average body weight of the control group) $\dagger$

(Mean values with their standard errors)

\begin{tabular}{|c|c|c|c|c|c|}
\hline & \multirow[b]{2}{*}{$n$} & \multicolumn{2}{|c|}{ TEE $(\mathrm{kJ} / 22 \mathrm{~h})$} & \multicolumn{2}{|c|}{$\operatorname{BEE}(\mathrm{kJ} / 22 \mathrm{~h})$} \\
\hline Group & & Mean & $\mathrm{SE}$ & Mean & $\mathrm{SE}$ \\
\hline Control & 17 & 173.9 & $4 \cdot 0$ & $111 \cdot 4$ & $4 \cdot 5$ \\
\hline MR & 6 & $170 \cdot 6$ & $6 \cdot 3$ & $105 \cdot 1$ & 5.5 \\
\hline \multicolumn{6}{|l|}{ SR: } \\
\hline Days $1-5$ & 5 & $141 \cdot 7 * * *$ & $3 \cdot 2$ & $118 \cdot 2$ & 0.8 \\
\hline Days $6-10$ & 5 & $132 \cdot 3 * * *$ & $2 \cdot 9$ & $106 \cdot 4$ & $1 \cdot 7$ \\
\hline
\end{tabular}

Mean value for SR rats was significantly different from control values: $* * * P<0.001$.

$\dagger$ For details of diets and experimental procedures, see pp. 422-423.

Table 4. Effect of mild $(M R)$ and severe $(S R)$ feed restriction on the energy expended in relation to activity in rats $\dagger$

\begin{tabular}{|c|c|c|c|c|c|c|c|c|c|}
\hline \multirow[b]{2}{*}{ Group } & \multirow[b]{2}{*}{$n$} & \multicolumn{2}{|c|}{$\begin{array}{l}\mathrm{BW} \\
(\mathrm{g})\end{array}$} & \multicolumn{2}{|c|}{$\begin{array}{c}\text { EE-Act } \\
(\mathrm{kJ})\end{array}$} & \multicolumn{2}{|c|}{$\begin{array}{c}\text { EE-Act } \\
(\mathrm{kJ} / 100 \mathrm{~g} \mathrm{BW})\end{array}$} & \multicolumn{2}{|c|}{$\begin{array}{c}\text { EE-Act } \\
(\% \text { of TEE })\end{array}$} \\
\hline & & Mean & $\mathrm{SE}$ & Mean & $\mathrm{SE}$ & Mean & $\mathrm{SE}$ & Mean & $\mathrm{SE}$ \\
\hline Control & 17 & 308 & 12 & $18 \cdot 6$ & $1 \cdot 4$ & $6 \cdot 1$ & 0.5 & $10 \cdot 85$ & 0.86 \\
\hline MR & 6 & $265^{*}$ & 2 & $18 \cdot 8$ & $3 \cdot 5$ & $7 \cdot 1$ & 0.5 & 12.95 & 0.79 \\
\hline \multicolumn{10}{|l|}{ SR: } \\
\hline Days $1-5$ & 5 & 308 & 12 & $14 \cdot 1$ & 1.8 & $4 \cdot 6$ & 0.6 & 9.97 & 1.09 \\
\hline Days 6-10 & 5 & 275 & 10 & $9 \cdot 3^{* *}$ & $1 \cdot 2$ & $3 \cdot 4^{* *}$ & 0.4 & $8 \cdot 16$ & 1.21 \\
\hline
\end{tabular}

BW, Body weight; EE-Act, energy expenditure due to activity.

Mean values for rats given a restricted feed intake were significantly different from control values: ${ }^{*} P<0 \cdot 005$, ** $P<0.01$.

$\dagger$ For details of diets and experimental procedures, see pp. 422-423.

by feed restriction (Table 5). That feed restriction did not result in a reduction in TEF, even in the SR rats, was further demonstrated by the fact that TEF did not show any decreasing trend throughout the $10 \mathrm{~d}$ of severe feed restriction. However, as a result of feed restriction per se, TEE due to feeding decreased to less than $9 \mathrm{~kJ}$ in the SR rats compared with an average $32 \mathrm{~kJ}$ in the control and MR rats.

Near basal energy expenditure. This variable was computed according to the principle that, in conditions where thermoregulatory efforts are minimized (that was the case in these experiments performed at $26^{\circ}$ ), basal energy expenditure is the energy expenditure that remains after the energy expended in relation to activity and feeding is subtracted from TEE. This calculation showed that when the fraction of energy expended in relation to activity and feeding was subtracted from TEE no more significant difference appeared in the near basal energy expenditure of the rats from the various groups (Tables 1 and 2, Fig. $1)$.

$R Q$. Table 6 shows that MR rats had RQ levels similar to the levels measured in the control rats, and close to the RQ reflecting the oxidation of the food (0.935). This finding indicates that these rats had adapted to the restricted feeding and were able to cover their 
Table 5. Effect of mild $(M R)$ and severe $(S R)$ feed restriction on thermic effect of feed in rats $\dagger$

\begin{tabular}{|c|c|c|c|c|c|c|c|}
\hline & \multirow[b]{2}{*}{$n$} & \multicolumn{2}{|c|}{$\begin{array}{c}\mathrm{FI} \\
(\mathrm{kJ})\end{array}$} & \multicolumn{2}{|c|}{$\begin{array}{l}\text { TEF } \\
\text { (kJ) }\end{array}$} & \multicolumn{2}{|c|}{$\begin{array}{c}\text { TEF } \\
(\% \text { FI })\end{array}$} \\
\hline & & Mean & $\mathrm{SE}$ & Mean & $\mathrm{SE}$ & Mean & $\mathrm{SE}$ \\
\hline Control & 6 & 211 & $18 \cdot 6$ & $31 \cdot 6$ & $2 \cdot 1$ & $15 \cdot 0$ & $0 \cdot 5$ \\
\hline MR & 6 & 227 & 0.0 & 32.5 & $2 \cdot 1$ & $14 \cdot 3$ & 0.9 \\
\hline \multicolumn{8}{|l|}{ SR: } \\
\hline Days $1-5$ & 5 & $56^{* *}$ & $0 \cdot 0$ & $8 \cdot 8 * *$ & $2 \cdot 7$ & $15 \cdot 7$ & $4 \cdot 8$ \\
\hline Days 6-10 & 5 & $56^{* *}$ & 0.0 & $8.9 * *$ & 1.5 & 15.9 & $2 \cdot 7$ \\
\hline
\end{tabular}

TEF, Thermic effect of feed; FI, feed intake in $\mathrm{kJ}=\mathrm{FI}(\mathrm{g}) \times 13 \cdot 3(\mathrm{~kJ} / \mathrm{g})$.

Mean values of SR rats were significantly different from control values: $* * p<0.01$.

$\dagger$ For details of diets and experimental procedures, see pp. 422-423.

Table 6. Effects of mild $(M R)$ and severe $(S R)$ feed restriction on the respiratory quotient $(R Q)$ in rats $\dagger$

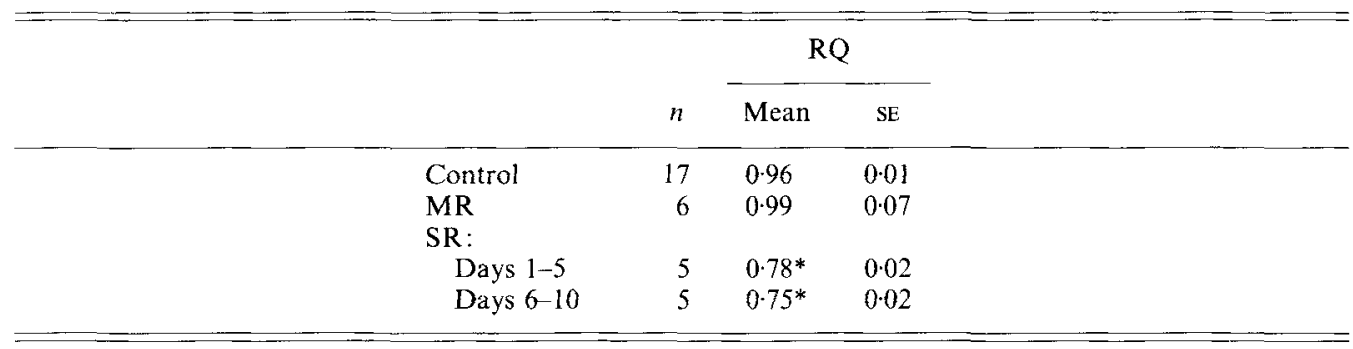

Mean values of SR rats were significantly different from control values: ${ }^{*} P<0.0001$.

$\dagger$ For details of diets and procedures, see pp. 422-423.

daily energy requirements without mobilizing their endogenous fat reserves. In contrast, a significant decrease in RQ was observed in the SR rats as soon as the second day of feed restriction. This finding clearly points out that an important part of the daily metabolic requirements of the SR rats was supplied by the utilization of their endogenous lipid stores.

\section{DISCUSSION}

Using a new-generation open-circuit calorimeter capable of monitoring the cost of activity and thereby both the real TEF and basal metabolism in free-moving rats, it was possible to reassess the proposal that an adaptive reduction in energy expenditure participates in the achievement of energy balance when feed intake is restricted. This experiment shows that in the absence of thermoregulatory effort, and when body weight is reduced by feed restriction rather than by starvation, TEE certainly decreases, but this decrease is essentially due to the fact that reduced feeding produces reduced TEF (although the same TEF per $g$ feed ingested) and that a lighter, less active, animal spends less energy in activity than a heavier, more active, animal.

Although the idea of an adaptive economy in each of the components of energy expenditure has often been questioned (McCarter et al. 1985, 1989; Yu et al. 1985), it is attractive and generally accepted (Benedict \& Fox, 1934; Westerterp, 1977; Apfelbaum, 1978; Forsum et al. 1981; Bessard et al. 1983; Hill et al. 1985). Therefore, it is important 
to consider the reasons that may account for the lack of evidence of adaptive metabolic changes in the present experiment.

One of the reasons, perhaps the main reason, is that in the present investigation, locomotor activity, a costly as well as unpredictable component of TEE, was measured continuously during the normal living behaviour of the subjects. This measure showed that spontaneous activity decreased in SR rats. Such a reduction in activity decreases postprandial TEE and, in previous studies, this decrease in TEE was inevitably taken as a reduction either in TEF or in resting or basal energy expenditure. The present study clearly demonstrates that both TEF and the basal metabolic rate can be estimated and compared only when the various components of metabolism have been distinctly monitored.

Another reason that may account for the lack of adaptative metabolic changes is that feed restriction rather than total starvation was utilized to decrease body weight. Feed restriction was preferred primarily because in humans the most usual conditions in body weight loss are those of partial suppression of foods (famines, pathologies or cosmetics). Also, total starvation results in an impairment of gastrointestinal functions including digestion, absorption, transport and postabsorptive processing, due to starvation diabetes and other disturbances (Marrazzi, 1940; Kotler et al. 1982). Therefore, a decreased TEF after total starvation may result from such impairments in the utilization of the ingestants rather than from adaptative mechanisms aimed at reducing TEF. In contrast, the preservation of some feeding, even severely reduced, respects or slightly improves the transport capacity of the intestinal tract and the utilization of the ingestants (Kershaw et al. 1960).

For the sake of appropriate comparisons, a large control group of ad lib.-fed rats of various body weights ( $220-450 \mathrm{~g})$ and ages (6-12 weeks) was used. However, comparing the energy expenditure of rats of different ages is of great concern. Therefore, we first studied the regression of TEE with age in the pool of control rats. This allowed us to verify that TEE increased linearly with body weight (and age), which would indicate that in these experiments the age of the rats remained in a sufficiently narrow range of adult life to have prevented a possible decrease of energy expenditure with age. This observation also agrees with a similar study conducted by Dulloo \& Girardier (1990), who verified that the maintenance requirements, and the efficiency of utilization above maintenance, remained unchanged in 7-11-week-old male Sprague-Dawley rats. Such observations would allow one to generalize the use of a growing population of rats as a control group that covers the entire range of body weights to be compared with those obtained by means of starvation. In addition, it is interesting that body weight, rather than its level raised to the power 0.75 or 0.62 , best correlated with energy expenditure and was the variable that provided a correlation with TEE that did not significantly diverge from the 0 intercept. This observation agrees with other reports (Cumming \& Morrison, 1960; Westerterp, 1977) and warns that the Brody-Kleiber coefficient must be used with great care when adjusting energy expenditure for a standardized body weight within the same species (see also Heusner, 1984).

Feed restriction modifies the activity of the rat but the direction of this modification depends on the strain and on the level of restriction as well as on the kind of activity measured (e.g. wheel running v. spontaneous activity) (Richter \& Rice, 1954; McNab, 1963; Morrison, 1968; Westerterp, 1977). In our experimental conditions most of the spontaneous activity of the ad lib.-fed rats was associated with feeding. In contrast, since the number of meals and total duration of feeding was strongly reduced during both levels of feed restriction, the activity was primarily extraprandial in the feed-restricted rats, as if they were actively foraging (Richter \& Rice, 1954). Some of this increase in intermeal activity may also be related to the reduction in duration of sleep (Danguir \& Nicolaidis, 1980 ) or to the fact that activity may have a beneficial action on the enhancement of 
physiological processes allowing for a better conservation of the body protein pool (Hill et al. 1987). Therefore, in a way, activity appeared to resist strongly feed restriction because it was observed to remain much larger than could be expected from the time spent in feeding behaviour. It was only after $5 \mathrm{~d}$ of severe feed restriction that the total activity of the SR rats decreased and so contributed to reducing TEE but via a behavioural, not a biochemical, mechanism.

Surprisingly, TEF expressed as a percentage of ingested energy remained invariable in MR as well as SR rats. Such a result agrees with the findings of Bessard et al. (1983) in obese women and Piers et al. (1992) in undernourished humans, but not with the majority of previous reports (Boyle et al. 1981; Hill et al. 1985; Harris et al. 1986; Vaisman et al. 1991). One could argue that the difference in the pattern of feed intake could have been artificially responsible for the persistence of an identical TEF since the restricted rats ate their meals in less numerous and larger meals than the ad lib.-fed controls, a pattern which would increase TEF (Tai et al. 1991) and, thus, hide the fact that under identical conditions TEF would have appeared reduced in the feed-restricted rats in comparison with ad lib.fed ones. However, first, this pattern replicated during the experimental measurements the one that was involved in the day-to-day energy balance of the rats, and we considered that TEF had to be measured under these usual living conditions; second, the fact that TEF did not show any trend to decrease in SR rats (for which the pattern of feed intake remained constant) throughout the $10 \mathrm{~d}$ of feed restriction is in favour of a real constancy of TEF during feed restriction. Therefore, if less energy was indeed dissipated in relation to feeding in SR rats it was only as a result of the strongly reduced feed intake. It can be concluded that the present study reveals the absence of a facultative component of thermogenesis in these lean rats and raises the question of the very existence of such a component in the $a d$ lib.-fed rat, if not in overweight subjects in general (Hervey \& Tobin, 1983; Trayhurn \& James, 1985).

It is difficult to come to any definite conclusion about adaptation in relation to basal energy expenditure without a precise assessment of body composition. Indeed, the small decrease in energy expenditure (on a body weight basis) revealed by the present study should have been magnified by assigning basal metabolism to a possibly reduced lean body mass of the feed-restricted rats. However, since mild feed restriction was reported to affect body protein content minimally (McCarter \& McGee, 1989; Dulloo \& Girardier, 1990), it is probable that in these rats assignment of the basal metabolism to lean body mass would only modify slightly the present results based on body weight. In contrast, the changes would certainly have been more pronounced in SR rats whose rapid body weight loss was primarily due to the utilization of fat stores, as previously reported (Hill et al. 1985) and clearly indicated in the present experiment by the maintenance of a low RQ throughout the procedure of severe feed restriction. Such a phenomenon leading progressively to a proportionally larger lean body mass is probably responsible for the paradoxical increase in the basal energy expenditure per unit body weight of SR rats during the first part of the severe feed restriction (see Tables 2 and 3). Therefore, it is possible that on a lean body mass basis the decrease in basal energy expenditure could have reached a 10 to $15 \%$ level in SR rats, instead of $4.5 \%$ as reported here on a bodyweight basis. No doubt, a precise estimation of an 'adaptative' decrease of basal energy expenditure during feed restriction will require further investigations including carcass analyses.

The comparison of the metabolic adaptations between the two feed-restricted groups may raise some questions because at the time the measurements were performed one of the groups was in the process of gaining body weight (MR) whilst the other was losing weight (SR). Indeed, the MR rats adapted to the lower availability of feed and could have continued to endure such a feed restriction for the rest of their lives. By doing so they had to deal with the relatively large cost of feeding, digesting, absorbing and storing then 
releasing energy-containing substrates. One could expect that under such conditions in which feed is available with scarcity but is, however, sufficient for survival, all possible adaptative mechanisms able to help reduce energy expenditure would have been stimulated. The situation was different in SR rats because in these animals a large proportion of their daily energy requirements was covered by the utilization of their endogenous fat reserves, which made them save some energy that was dissipated under feeding thermogenesis in the other groups. Therefore, direct comparison of their TEE or feeding-associated energy expenditure with those in the other rats, either ad lib.-fed or MR, should be considered with caution.

In fact, the near complete absence of metabolic adaptations in both feed-restricted groups in the present study finally suggests that the metabolic machinery was already functioning with optimal efficiency under ad lib. feeding. In addition, the obvious capacity of the rats to remain in good shape despite their pronounced weight loss would indicate that under $a d$ lib. feeding the regulation of body weight is performed at a level much larger than strictly necessary, a sort of 'security' level. This is also supported by the observation that the maintenance of a mildly restricted feed intake throughout the life of the rat has a beneficial effect on health and increases longevity (McCarter et al. 1985; Yu et al. 1985). Waterlow (1986) stated that: 'At any given height, there is a range in body weight consistent with health. There is no reason, therefore, why a reduction in body weight should not be accepted as a part of the process of adaptation to low intakes, provided that weight remains within acceptable limits.' It can be suggested that the main, if not the only, adaptation to feed restriction would be the maintenance of large energy stores during periods of abundance.

In conclusion, our measurements do not fully support the idea, however attractive, according to which any decrease in feed intake should result in a proportional, adaptive decrease in energy expenditure. This lack of adaptation seems particularly true under a condition of feed restriction that allows long-term survival of the subject, which is the most common situation occurring in humans and for which the question of energy efficiency is raised. In spite of the fact that the adaptative changes in metabolism are minimal and restricted to basal metabolism, a pool of concurrent processes contribute to reducing the spillage of energetic substrata as body weight decreases and food remains scarce. These concurrent processes consist of the progressive reduction in energy expended in relation to activity and feeding (due to the restriction of the food itself), in the possible decrease in basal energy expenditure and most of all in the reduced body mass that has to be displaced and nourished.

This work was supported by grants from C.N.R.S. and MRT 88G-0523. The authors are indebted to Dr N. Carlson and S. N. Thornton for their help in the improvement of the manuscript.

\section{REFERENCES}

Apfelbaum, M. (1978). Adaptation to changes in caloric intake. Proceedings of Food and Nutrition Sciences 2 , $543-559$.

Benedict, F. G. \& Fox, E. L. (1934). Protein and energy metabolism of wild albino rats during prolonged fasting. American Journal of Physiology 108, 285-294.

Bessard, T., Schutz, Y. \& Jequier, E. (1983). Energy expenditure and post-prandial thermogenesis in obese women after weight loss. American Journal of Clinical Nutrition 36, 680-694.

Boyle, P. C., Storlin, L. H., Harper, A. E. \& Keesey, R. E. (1981). Oxygen consumption and locomotor activity during restricted feeding and realimentation. American Journal of Physiology 241, R392-R397.

Cumming, M. C. \& Morrison, S. D. (1960). The total metabolism of rats during fasting and refeeding. Journal of Physiology 100, 219-243.

Danguir, J. \& Nicolaïdis, S. (1980). Intravenous infusions of nutrients and sleep in the rat: an ischymetric sleep regulation hypothesis. American Journal of Physiology 238, E307-E312.

Dulloo, A. G. \& Girardier, L. (1990). Adaptative changes in energy expenditure during refeeding following low- 
calorie intake: evidence for a specific metabolic component favoring fat storage. American Journal of Clinical Nutrition 52, 415-420.

Even, P., Coulaud, H. \& Nicolaïdis, S. (1988). Lipostatic and ischymetric mechanisms originate dexfenfluramine induced anorexia. Pharmacology, Biochemistry and Behavior 30, 89-99.

Even, P. \& Nicolaïdis, S. (1981). Changes in the efficiency of ingestant are a major factor of regulation of energy balance. In The Body Weight Regulatory System: Normal and Disturbed Mechanisms, pp. 115-123 [L. A. Cioffi et al., editors]. New York: Raven Press.

Even, P. \& Nicolaidis, S. (1984). Le métabolisme de fond: Définition et dispositif de mesure (The background metabolism: definition and measuring device). Compte Rendu des Séances de l'Académie des Sciences (Paris) 298, 261-266.

Even, P. \& Nicolaïdis, S. (1985). Spontaneous and 2DG induced metabolic changes and feeding: the ischymetric hypothesis. Brain Research Bulletin 14, 429-435.

Even, P., Perrier, E., Aucouturier, J. L. \& Nicolaïdis, S. (1991). Utilization of the method of Kalman filtering for the on-line computation of background metabolism in the free-moving free-feeding rat. Physiology and Behavior 49, 177-187.

Forsum, E., Hilman, P. E. \& Nesheim, M. C. (1981). Effect of energy restriction on total heat production, basal metabolic rate, and specific dynamic action of food in rats. Journal of Nutrition 111, 1691-1697.

Harris, R. B. S., Thomas, R. K. \& Martin, R. L. (1986). Dynamics of recovery of body composition after overfeeding, food restriction and starvation. Journal of Nutrition 116, 2536-2546.

Hervey, J. R. \& Tobin, G. (1983). Luxuxkonsumption, diet induced thermogenesis and brown fat: a critical review. Clinical Science 64, 7-18.

Heusner, A. A. (1982). Energy metabolism and body size. I. Is the 0.75 mass exponent of Kleiber's equation a statistical artifact? Respiratory Physiology 48, 1-12.

Heusner, A. A. (1984). Biological similitude: statistical and functional relationships in comparative physiology. American Journal of Physiology 246, R839-R845.

Hill, J. O., Latiff, A. \& DiGirolamo, M. (1985). Effects of variable caloric restriction on utilization of ingested energy in rats. American Journal of Physiology 17, R549-R559.

Hill, J. O., Starling, P. B., Shields, T. W. \& Heller, P. A. (1987). Effects of exercise and food restriction on body composition and metabolic rate in obese women. American Journal of Clinical Nutrition 46, 622-630.

Kershaw, T. G., Neame, K. D. \& Wiseman, G. (1960). The effect of semistarvation on absorption by the rat small intestine in vitro and in vivo. Journal of Physiology 152, 182-190.

Kleiber, M. (1947). Body size and metabolic rate. Physiological Reviews 7, 511-541.

Kotler, D. P., Kral, J. G. \& Björntorp, P. (1982). Refeeding after a fast in rats: effects on small intestinal enzymes. American Journal of Clinical Nutrition 36, 457-462.

Lusk, G. (1928). The Elements of the Science of Nutrition, 4th ed. Philadelphia: W. W. Saunders.

McCarter, R. J. \& McGee, J. R. (1989). Transient reduction of metabolic rate by food restriction. American Journal of Physiology 257, E175-E179.

McCarter, R. J., Masoro, E. J. \& Yu, B. P. (1985). Does food restriction retard aging by reducing metabolic rate? American Journal of Physiology 248: E488-E492.

McNab, B. K. (1963). A model of the energy budget of the wild mouse. Ecology 44, 521-532.

Marrazzi, R. (1940). The influence of adrenalectomy and of fasting on the intestinal absorption of carbohydrates. American Journal of Physiology 131, 36-42.

Morrison, S. D. (1968). The constancy of the energy expended by rats on spontaneous activity, and the distribution of activity between feeding and non-feeding. Journal of Physiology 197, 305-323.

Piers, L. S., Soares, M. J. \& Shetty, P. S. (1992). Thermic effect of a meal. 2. Role in chronic undernutrition. British Journal of Nutrition 67, 177-185.

Richter, C. P.\& Rice, K. K. (1954). Comparison of the effect produced by fasting on gross bodily activity of wild and domesticated Norway rats. American Journal of Physiology 179, 305-308.

Rothwell, N. J. \& Stock, M. J. (1984). Energy balance, thermogenesis and brown adipose tissue activity in tubefed rats. Journal of Nutrition 114, 1965-1970.

Tai, M. M., Castillo, P. \& Pi-Sunyer, F. X. (1991). Meal size and frequency: effect on the thermic effect of food. American Journal of Clinical Nutrition 54, 783-787.

Trayhurn, P. \& James, W.P. T. (1985). Thermogenesis: dietary and non-shivering aspects. In Body Weight Regulatory System: Normal and Disturbed Mechanisms, pp. 97-105 [L. A. Cioff, W. P. T. James and T. B. Van Itallie, editors]. New York: Raven Press.

Vaisman, N., Rossi, M. F., Corey, M., Clarke, R., Goldberg, E. \& Pencharz, P. B. (1991). Effect of refeeding on the energy metabolism of adolescent girls who have anorexia nervosa. European Journal of Clinical Nutrition 45, 527-537.

Waterlow, J. C. (1986). Metabolic adaptation to low intakes of energy and protein. Annual Review of Nutrition 6, 495-526.

Westerterp, K. (1977). How rats economize energy loss in starvation. Physiological Zoology 50, 331-362.

Yu, B. P., Masoro, E. J. \& McMahan, C. A. (1985). Nutritional infuences on aging of Fisher 344 rats. I. Physical, metabolic and longevity mechanisms. Journal of Gerontology 40, 657-670. 